\title{
Survey of Preventive Services by General Dental Practitioners in
} Zahedan, 2016

\author{
Elham Bozorgmehr, ${ }^{1,}$ Hossein Ansari, ${ }^{2}$ Mahsa Poordavar, and Azam Dahmardeh Ghalenou ${ }^{1}$ \\ ${ }^{1}$ Department of Community Dentistry, School of Dentistry, Zahedan University of Medical Sciences, Zahedan, Iran \\ ${ }^{2}$ Health Promotion Research center, Zahedan University of Medical Sciences, Zahedan, Iran \\ "Corresponding author: Elham Bozorgmehr, Department of Community Dentistry, School of Dentistry, Zahedan University of Medical Sciences, Zahedan, Iran. Tel: \\ +98-9151906654, Fax: +98-5433414003, E-mail: bozorgmehr.e@gmail.com
}

Received 2016 January 02; Revised 2016 January 19; Accepted 2016 February 21.

\begin{abstract}
Background: General dental practitioners are important resources for implementing preventive strategies and meeting dental treatment needs. Dental education plays a vital role in providing the community with dental practitioners who are equipped with the ability to apply preventive dental care.

Objectives: Considering the importance of preventive practices by dentists, this study was designed to assess preventive services by general dental practitioners working clinically in Zahedan, southeast of Iran.

Methods: This cross sectional study was carried out among general dental practitioners in Zahedan, southeast of Iran. A total of 105 participants were invited to the study, of whom 95 participants had completed questionnaires on all the variables selected for analysis (response rate $=86 \%$ ). A self-administrated structured questionnaire was used to collect the data. $\mathrm{P}=0.05$ was considered as the significance level.

Results: Among all the participants, 51.6\% always gave oral hygiene instructions and $35.8 \%$ gave nutrition instructions to their patients. Only $20 \%$ of them always advised patients to use fluoride and $34.7 \%$ did fluoride therapy for most children. Fissure sealant was done by $48.4 \%$ for most children who needed it. According to the Chi-square test, there was no significant relationship between gender and health instructions $(\mathrm{P}=0.86)$, but the relationship was significant between performing fissure sealant $(\mathrm{P}=0.03)$ and fluoride therapy $(\mathrm{P}=0.05)$, so that female general dental practitioners provided fluoride therapy and fissure sealant more than males. Fissure sealant has also a significant relationship with the participants' age $(\mathrm{P}=0.001)$ and the years since their graduation $(\mathrm{P}=$ $0.03)$, so that younger and more newly graduated ones performed fissure sealants more than the others. There was a significant relationship between providing health education $(P=0.044)$, nutrition education $(P=0.01)$, and fissure sealant $(P=0.04)$ with the location of graduation, as the participants who were educated abroad had done better than those graduated in the country. Conclusions: Preventive dental services are not performed by the majority of the general dental practitioners in the southeast of Iran. Also, raising the awareness of the people about preventive methods and considering insurance for preventive services can help to promote dental caries prevention.
\end{abstract}

Keywords: Preventive Dental Services, General Dentists, Barriers to Prevention

\section{Background}

Dental caries is one of the most common diseases which can have a great impact on the quality of life. However, dental caries can be reduced or eliminated by applying preventive dental practices and early intervention strategies at public and individual levels. Studies have shown that the widespread use of fluorides has accounted for the declining dental caries in the developed countries at the end of the $20^{\text {th }}$ century (1). On the other hand, the prevalence of dental caries in developing countries has remained high which might be explained by less preventive oriented dental services (2). Preventive dentistry is recognized as an integral part of modern dental services (1). The world health organization (WHO) recommended orienting dental services towards prevention as a priority action area for developing countries when initiating oral health programs $(1,3)$. However, preventive practices are not fully implemented by dentists $(1,4)$. New reports from some countries have suggested a high prevalence of dental caries and unmet treatment needs among children $(1,5$, $6)$. Dentists are important resources for implementing preventive strategies and meeting dental treatment needs (7). Dental education plays a vital role in providing the community with dental practitioners who are equipped with the ability to apply preventive dental care $(1,8,9)$.

\section{Objectives}

Considering the importance of preventive practices by dentists, this study was designed to assess preventive services by general dental practitioners working clinically in 
Zahedan.

\section{Methods}

This cross sectional study was carried out in 2016 among general dental practitioners working in Zahedan, southeast of Iran. A total of 105 dentists were invited to participate in this study, of whom 95 participants had completed questionnaires on all the variables selected for analysis (response rate $=86 \%$ ). A self-administrated structured questionnaire was used to collect the data which was distributed in person and collected the next day. The participants were asked to provide demographic information (sex and age). Information that could identify the dentists' identity was not requested, so that they were encouraged to provide truthful information. The questionnaire was piloted among 10 dentists for clearance and understanding. After fixing the problems, these questionnaires were included in the final analysis. Dentists were divided into two age groups including below and above 30 years old. Regarding job experience, the dentists were divided into two groups including below and over 10 years. The informed consent was obtained from all the participants and this study was approved in the ethical committee in Zahedan University of Medical Sciences.

Ethical codes 1, 15, 28, 29, 31, and 15 in accordance with the general guidelines of ethics in medical research with human subjects in the Islamic Republic of Iran are considered in this study.

The data were presented using descriptive and inferential statistics including statistical tables, central and dispersion indices. The Chi-square test was used to analyze the data. The data were analyzed using SPSS.21 software and $\mathrm{P} \leq 0.05$ was set as the significance level.

\section{Results}

Out of all 105 general dental practitioners working clinically in Zahedan, 95 dentists participated in this study, out of which 57 (60\%) were male and 38 (40\%) were female. The average age of participants was $35.73 \pm 7.9$ years and the average work experience was $9.9 \pm 7.6$ years. A total of 89 dentists $(93.7 \%)$ had graduated from Iranian universities and only 6 (7.3\%) from abroad.

Among all general dental practitioners, 49 (51.6\%) always gave oral hygiene instructions and 49 (35.8\%) gave nutritional instructions to their patients. Only 19 (20\%) of them always advised patients on using fluoride and 33 (34.7\%) did fluoride therapy for most children. Fissure sealant was done by 46 (48.4\%) of the participants for most children who needed it. About 39 (41.1\%) of them claimed that they asked patients how they brushed their teeth. A total of $78 \%$ gave recommendation to parents about preventive dentistry and $75.8 \%$ emphasized on the role of preventive services and their importance for parents and children (Table 1). Most of general dental practitioners reported that they spent less than 10 minutes for health education to each patient. The participants' opinion about barriers of preventative care to patients included the reluctance of patients, lack of sufficient time, not being affordable, and the lack of awareness about prevention methods. General dental practitioners suggested spending more time in the field of prevention, increasing insurance for the prevention, and learning better methods of prevention (Table 2).

According to Chi-square test, there was not a significant relationship between gender and health instructions $(\mathrm{P}=0.86)$, but the relationship was significant between performing fissure sealant $(\mathrm{P}=0.03)$ and fluoride therapy $(\mathrm{P}$ $=0.05$ ), so that female dentists provided fluoride therapy and fissure sealant more than males.

Performing fissure sealant was significantly related to the dentists' age $(\mathrm{P}=0.001)$ and the years since their graduation $(\mathrm{P}=0.03)$, so that younger and more newly graduated dentists performed fissure sealants more than the others.

The Chi-square, also, showed that there was a significant relationship between providing health education $(\mathrm{P}=$ $0.044)$, nutrition education $(\mathrm{P}=0.01)$, and performing fissure sealant $(\mathrm{P}=0.04)$ with the location of graduation; the dentists who had been educated abroad had done better than the participants graduated in the country, Iran.

\section{Discussion}

A total of 95 general dental practitioners participated in this study and the information about preventive services was collected in a questionnaire that was distributed between them.

This study shows that general dental practitioners do not adequately fulfill their role in providing preventive dental services. The findings of this study are in accordance with some studies regarding preventive services by dentists. The study by Pourasghar Moghaddam in 2001 in Anzali port and Rasht showed that $47 \%$ of the dentists in Rasht and 38.1\% in Anzali gave their patients' health education (10). The results of this study in Iran are approximately similar to our results.

In a study by Friedman in $2006,81 \%$ of dentists reported that they provided health instruction to their patients (11), as well, in a study by Treasure, the majority of the samples reported routinely providing oral hygiene (95.7\%) and diet advices (85.4\%) (12), so the dentists in these studies provided more health instruction to their patients compared to our study. This contradiction may be related to 
Table 1. The Frequency of Preventive Services By General Dental Practitioners in Zahedan, 2016

\begin{tabular}{|c|c|c|c|}
\hline Preventive Services & Preventive Services Status & Number & Percent \\
\hline \multirow{3}{*}{ Oral health education } & Always & 49 & 51.6 \\
\hline & Sometimes & 45 & 47.4 \\
\hline & Never & 1 & 1.1 \\
\hline \multirow{2}{*}{ Nutrition education } & Always & 34 & 35.8 \\
\hline & Never & 4 & 4.2 \\
\hline \multirow{3}{*}{ Fluoride mouth rinse education } & Always & 19 & 20.0 \\
\hline & Sometimes & 75 & 78.9 \\
\hline & Never & 1 & 1.1 \\
\hline \multirow{3}{*}{ Topical fluoride therapy } & Always & 33 & 34.7 \\
\hline & Sometimes & 50 & 52.6 \\
\hline & Never & 12 & 12.7 \\
\hline \multirow{3}{*}{ Fissure sealant } & Always & 46 & 48.4 \\
\hline & Sometimes & 40 & 42.1 \\
\hline & Never & 9 & 9.5 \\
\hline \multirow{3}{*}{ Disclosing agent for tooth Brushing education } & Always & 2 & 2.1 \\
\hline & Sometimes & 55 & 57.9 \\
\hline & Never & 38 & 40.0 \\
\hline
\end{tabular}

Table 2. The Distribution of Barriers in Providing Preventive Services and Recommendations to Increase Services By General Dental Practitioners in Zahedan, $2016^{\mathrm{a}}$

\begin{tabular}{|c|c|c|c|}
\hline Preventive Services & Preventive Services Status & Number & Percent \\
\hline \multirow{4}{*}{ Barriers to provide preventive services } & Not enough time & 36 & 37.9 \\
\hline & Lack of awareness of preventive methods & 3 & 3.1 \\
\hline & The reluctance of the patients & 47 & 49.47 \\
\hline & Not affordable & 8 & 8.42 \\
\hline \multirow{3}{*}{ Recommendations to increase preventive services } & Learning better methods of prevention & 31 & 32.6 \\
\hline & Insurance for preventive services & 48 & 50.52 \\
\hline & Creating awareness and interest in patients & 73 & 76.8 \\
\hline
\end{tabular}

${ }^{\mathrm{a}}$ Some cases did not respond to the questions, so there were missing items and in some cases, respondents could choose more than one option and, therefore, the sum of percentages exceeds 100 percent.

the education of preventive dentistry for dental students in Iran.

Despite the positive effects of fluoride $(13,14)$, only $20 \%$ of general dental practitioners recommend fluoride mouth rinse and $34.7 \%$ do fluoride therapy for children. These findings can show that the application of fluoride is low according to the percentage of recommendation to patients about the use of fluoride. Also, in Ghasemi's study, $20 \%$ to $25 \%$ of dentists considered the use of fluoride (15).

In reviewing, a study in 2010 in Taiwan has shown that the sealants is an effective factor in prevention, but $44 \%$ of general dental practitioners reported that they did fissure sealant only for less than $10 \%$ of the patients because of the lack of recognition of the importance of fissure sealant by the patients (16). In this study, $48.4 \%$ of dentists reported that they often did fissure sealants for patients who need sealants.

This study has shown that $8.42 \%$ of general dental practitioners explained that the reason for not providing preventive services is not being commercial. According to a study in 1994 reported by Holloway, dentists said preventive services are not economical (17). The same result was observed in a study in 2008 by Ghasemi (15). In the study by Treasure, it has been expressed that perceived barriers were related to the factors including insufficient remuneration (86.3\%) (12). 
About 37.9\% of the participants in the study believed that the reason for not providing preventive services is the lack of adequate time. In Tseveenjav's study in 2005, the lack of adequate time due to the high demand of patients for restorative services would be the cause of not providing prevention services (18). Lack of time (84\%) was also expressed in the study by Treasure (12).Yokoyama's study in 2013 explained that totally $10 \%$ of the working time of the dentists is spent for prevention services (19).

In the present study, no significant relationship between gender and health instructions was observed, but the relationship was significant between performing fissure sealant and fluoride therapy. A similar result was found by Silva (20). As well, the study by Treasure has shown that female dentists were more likely to provide fissure sealants and diet advices (12). No other differences were found by age and sex between the participants.

General dental practitioners who participated in the present study suggested increasing insurance for the prevention and learning better methods of prevention, also, the study in 2010 clearly showed that most of the preventive services were done for patients who had dental insurance and female dentists performed these services more (20).

Like the other questionnaire surveys, there may be over-representation, because the responding general dental practitioners may tend to be more interested in giving acceptable answers about their professional activity. To minimize this problem, information that could identify the dentists' identity was not requested, so that they were encouraged to provide true information.

The present study was not meant to be nationally representative, but it can be used to identify potential areas for further investigation.

\subsection{Conclusion}

Preventive dental services are not performed by the majority of the general dental practitioners in the southeast of Iran. Also, raising the awareness of the people about preventive methods and considering insurance for the preventive services can help to promote dental caries prevention.

\section{Footnotes}

Authors' Contribution: All authors contributed equally. Funding/Support: This paper has been extracted from an academic thesis $(\mathrm{n}=7612)$ in Zahedan Dental School, which was supported financially by Zahedan University of Medical Sciences.

\section{References}

1. Arheiam A, Bankia I, Ingafou M. Perceived competency towards preventive dentistry among dental graduates: the need for curriculum change. Libyan J Med. 2015;10:26666. doi: 10.3402/ljm.v10.26666. [PubMed: 25556523].

2. Moynihan P, Petersen PE. Diet, nutrition and the prevention of dental diseases. Public Health Nutr. 2004;7(1A):201-26. doi 10.1079/PHN2003589. [PubMed: 14972061].

3. Petersen PE. World Health Organization global policy for improvement of oral health-World Health Assembly 2007. Int Dent J. 2008;58(3):115-21. doi: 10.1111/j.1875-595X.2008.tb00185.x. [PubMed: 18630105].

4. Garcia RI, Sohn W. The paradigm shift to prevention and its relationship to dental education. J Dent Educ. 2012;76(1):36-45. [PubMed: 22262548].

5. Huew R, Waterhouse PJ, Moynihan PI, Maguire A. Prevalence and severity of dental caries in Libyan schoolchildren. Int Dent $J$. 2011;61(4):217-23. doi: 10.1111/j.1875-595X.2011.00060.x. [PubMed: 21851354].

6. Arheiam A, Omar S. Dental caries experience and periodontal treatment needs of 10- to 15-year old children with type 1 diabetes mellitus. Int Dent J. 2014;64(3):150-4. doi:10.1111/idj.12091. [PubMed: 24506709].

7. Arheiam A, Masoud I, Bernabe E. Perceived barriers to preventive dental care among Libyan dentists. Libyan J Med. 2014;9:24340. doi: 10.3402/ljm.v9.24340. [PubMed: 24767673].

8. McGlone P, Watt R, Sheiham A. Evidence-based dentistry: an overview of the challenges in changing professional practice. $\mathrm{Br}$ Dent $\mathrm{J}$. 2001;190(12):636-9. doi: 10.1038/sj.bdj.4801062a. [PubMed: 11453152].

9. Carson SJ, Freeman R. Training and fairer payments would increase caries prevention in practice. Evid Based Dent. 2015;16(1):6-7. doi: 10.1038/sj.ebd.6401072. [PubMed: 25909928].

10. Pourasghar Moghaddam. P. . Evaluation of knowledge, attitude and practice of dentists in Banda Anzali and Rasht about health education program [Thesis]. Tehran: Tehran University of Medical Sciences; 2001.

11. Friedman S, Leopold R. Preference for oral health services in us community. J Public Health Dent. 2006;60(4):248-54.

12. Treasure E. Summary of: Differences by age and sex in general dental practitioners' knowledge, attitudes and behaviours in delivering prevention. Br Dent J. 2015;219(6):264-5. doi: 10.1038/sj.bdj.2015.725. [PubMed: 26404989].

13. Ellwood R, Fejerskov O. Dental caries: the disease and its clinical management. Oxford: Blackwell Munksgaard; 2003. Clinical use of fluoride.

14. Edwina Kidd AM, Nyvad B, Espelid I. Dental caries. Blackwell Publishing Ltd; 2008. Caries control for the individual patient.

15. Ghasemi H. Preventive orientation and caries management by Iranian dentists. University of Helsinki; 2008.

16. Lin TH, Hsieh TY, Horowitz AM, Chen KK, Lin SS, Lai YJ, et al. Knowledge and practices of caries prevention among Taiwanese dentists attending a national conference. J Dent Sci. 2010;5(4):229-36. doi 10.1016/j.jds.2010.11.007.

17. Holloway PJ, Clarkson JE. Cost: benefit of prevention in practice. Int Dent J. 1994;44(4):317-22. [PubMed: 7822057].

18. Tseveenjav B, Vehkalahti MM, Murtomaa H. Barriers to the provision of oral health education among Mongolian dentists. Oral Health Prev Dent. 2005;3(3):183-8. [PubMed: 16355652].

19. Yokoyama Y, Kakudate N, Sumida F, Matsumoto Y, Gilbert GH, Gordan VV. Dentists' practice patterns regarding caries prevention: results from a dental practice-based research network. BMJ Open. 2013;3(9):e003227. doi:10.1136/bmjopen-2013-003227. [PubMed: 24068763].

20. Silva RP, de Salles Loureiro CA, Pereira CV, Flório FM. Profile of the dental surgeon related to the recommendation of individual preventive strategies. Brazil J Oral Sci. 2015;5(17):1022-7. 